\title{
Spatial regression approach to estimate synthetic unit hydrograph by geomorphic characteristics of watersheds in arid regions
}

\author{
Luminda N GUNAWARDHANA*, Ghazi A AL-RAWAS, Mahad S BAAWAIN \\ Department of Civil and Architectural Engineering, College of Engineering, Sultan Qaboos University, Oman
}

\begin{abstract}
Rainfall-runoff relationship in arid regions is unique and challenging to study. Studies for bridging the hydro-meteorological knowledge gap for planning, designing and managing water resources is therefore vitally important. The objective of this study is to develop a method for estimating unit hydrograph at reasonably finer time resolutions (10-min and 1-h) which can be easily adaptable by practitioners at subcatchment levels, especially when the focus area is ungauged. Observed wadi-flow at 5-min interval and tipping bucket rainfall measurements at 1-min interval were obtained to cover 10 major watersheds in Oman. The deconvolution method was applied to derive the unit hydrographs (UHs) from wadi-flow and excess rainfall. Key catchment characteristics such as the watershed area, length of the main wadi and the length to the centroid of the catchment area were derived from digital elevation model (DEM) data. The whole study area was then divided into 515 sub-catchments with various shapes and sizes. A strong relationship was found between the wadi length and the length to the centroid of the catchment area $\left(R^{2}>0.89\right)$. This relationship was then adopted to simplify the classical Snyder method to determine UHs. Moreover, several parameters of the Snyder method were calibrated to the arid environment by matching the peak-flow, lag-time and three time-widths $(75 \%, 50 \%$ and $30 \%$ of the peak-flow) of 10 -min and 1-h UHs with physical characteristics of the watersheds. All developed relationships were validated with independent rainfall and wadi-flow events. Results indicate that the calibrated parameters in these arid watersheds are quite distinct from those suggested for other regions of the world. A marked difference was found between the 10-min UHs estimated by the S-hydrograph method and the deconvolution method. Therefore, it is concluded that a method depends on natural hydro-meteorological conditions would be more practical in arid region. The proposed methodology can be used for water resources management in arid regions having similar climate and geographical settings.
\end{abstract}

Keywords: deconvolution method; S-hydrograph method; Snyder method; DEM data; river length

Citation: Luminda N GUNAWARDHANA, Ghazi A AL-RAWAS, Mahad S BAAWAIN. 2020. Spatial regression approach to estimate synthetic unit hydrograph by geomorphic characteristics of watersheds in arid regions. Journal of Arid Land, 12(6): 950-963. https://doi.org/10.1007/s40333-020-0101-y

\section{Introduction}

Floods are perhaps the most concern natural phenomenon in arid regions, which proved to have both positive and negative impacts. Moderate flood, which spread over a large area and been regulated by wide-opened channels, successive dikes and retention basins, can significantly

\footnotetext{
*Corresponding author: Luminda N GUNAWARDHANA (E-mail: luminda@squ.edu.om)

Received 2019-12-03; revised 2020-05-09; accepted 2020-10-14

(C) Xinjiang Institute of Ecology and Geography, Chinese Academy of Sciences, Science Press and Springer-Verlag GmbH Germany, part of Springer Nature 2020
} 
replenish the groundwater aquifers (Abdalla et al., 2013, 2014; Mayaud et al., 2019). Young et al. (2004) discovered freshwater lenses in the Central Oman shallow aquifers claimed to be formed by recharge water from infrequent cyclonic rainfall. In contrast, flash floods are rare but have been a potentially catastrophic hazard in many parts of the world (Badrzadeh et al., 2015; Ahmadalipour and Moradkhani, 2019) including the arid regions. For example, Cyclone Gonu in 2007 is considered to be the worst natural disaster in recorded history of Oman, which caused approximately 4.6 billion USD damage and 69 deaths.

Flash floods are affected by various hydro-metrological characteristics, most notably triggered by extremely heavy rainfall, but also intensify by steep slopes, poor vegetation cover, soils with low permeability and ephemeral streams (locally known as wadi) attributed to long dry periods (Ghoneim and Foody, 2013; Parsons, 2018). Damages caused by the flash floods exaggerate as population growth and asset progressively expands in flood-prone areas (Hering et al., 2004; Kazama et al., 2009; Merz et al., 2010). Most of the areas categorized into arid climate zones in Middle East region receive annual total rainfall less than $130 \mathrm{~mm}$ with occasional high intensity and short-duration storms, which can generate river flows rise from zero to peak within a few minutes up to a few hours (Greenbaum et al., 1998).

In addition to the difficulty with lack of gauging stations, river-flow simulation in arid regions present unique challenge due to rare occurrence of rainfall events and their greater spatial variability (Pilgrim et al., 1988). In response to these issues, hydro-metrological data network has been expanded and updated in various countries (Sen, 2008). As a result, many of the large watersheds in Oman have been equipped with river-gauge stations at their outlets, which provides an important opportunity to understand complex rainfall-runoff relationship in arid regions and will eventually enhance the clarity of water management and adaptation measures. Owing to population growth and industrialization, urbanization gradually expands from coastal valley areas to the upstream catchment areas in Oman. Planning and designing of various infrastructures such as roads, bridges, culvert and recharge dams warrant wadi-flow data, which are not yet available for many small and medium scale watersheds.

Traditional runoff simulation methods such as Sherman's unit hydrograph (UH) technique (Sherman, 1932) and Tank model (Sugawara, 1995) use concurrent rainfall and wadi-flow data to develop complete flood hydrographs at the catchment outlet resulted from arbitrary storms. In the absence of river-flow and rainfall data in ungauged catchments, synthetic UH method is widely used for hydrologic/hydraulic designs (Bhuyan et al., 2015; Tomirotti and Mignosa, 2017). As explained by Chow et al. (1988), there are three types of synthetic unit hydrographs (UHs): (1) those used geomorphological properties of the watershed to develop theoretical or empirical relationships for the UH characteristics such as the peak-flow rate and timing etc. (Snyder, 1938; Gray, 1961); (2) those based on dimensionless UH (Soil Conservation Service, 1972); and (3) those based on models of watershed storage (Clark, 1943).

Synthetic UH method does not depend on hydrological observations and is widely used in ungauged watersheds. However, parameters appeared in empirical relations are subjected to a great level of uncertainty when the original equations are applied with radically different hydrometeorological conditions. For example, Snyder (1938) developed a set of empirical equations for the time-lag and peak-flow of his proposed synthetic UH by analyzing runoff characteristics in a large number of drainage-areas (26-26,000 $\mathrm{km}^{2}$ ) in Appalachian Highland in eastern United State. Since then, many studies have been conducted to regionalize model parameters in many parts of the world. Borga et al. (1991) used the Snyder method for developing a real-time flood forecasting system in Italy. Usul and Tezcan (1995) developed UHs from runoff data for four catchment areas in Turkey. The characteristics of these UHs were then matched with the Snyder's synthetic UH to obtain a set of parameters best-fit with local site conditions. Jena and Tiwari (2006) applied a similar methodology in two medium sized agricultural watersheds and a set of model parameters applicable for West Bengal state in India were proposed. El Hassan et al. (2013) used the Snyder method embedded in the HEC-HMS software to simulate rainfall-runoff relationship of a semiurbanized catchment in Texas of the United States.

The main objective of this study was to develop a methodology that is easily adaptable for 
designing hydraulic structures in ungauged catchment areas. A set of type curves were presented to develop the UH based on three simple but important catchment characteristics: watershed area, length of the main wadi and length to the centroid of the watershed along the main wadi from its outlet. This relationship was developed based on Snyder's UH method but was easily operationalizable for practical designs in ungauged catchment areas. Most of the past studies selected coarse time durations (e.g., 1-h or 2-h) when developing UHs due to the absence of rainfall and wadi-flow in finer time resolutions. UHs with coarse time resolutions might not be accurately convertible to finer time durations to match with the intense and short-duration rainfall events common in arid regions. This study used wadi-flow data accumulated at 10-min intervals at the outlets of 12 watersheds with catchment area ranges from 45 to $1660 \mathrm{~km}^{2}$ in Oman. Concurrent rainfall data at 1-min interval collected using tipping bucket rain gauges at 37 stations were also obtained. These data at finer time resolutions provided a unique opportunity to understand complex hydrological response in arid regions (1-h and 10-min UHs).

\section{Study area}

Oman is located at the southeast strip of the Arabian Peninsula (Fig. 1). Densely populated urban cities, such as Sohar, Muscat (the capital city), Sur and Salalah are located along the $3165 \mathrm{~km}$ long coastal plain. A series of rugged mountains (with the highest peak of $3075 \mathrm{~m}$ above sea level) and the Ophiolite hills run parallel to most of the coastline. The interior region accounts for nearly $82 \%$ of the country and mainly consists of sandy deserts. The climate in Oman varies mainly from semiarid to hyper-arid. According to the records of 49 gauge stations over the 1985-2004 period, total annual rainfall ranges from $31 \mathrm{~mm}$ in the interior desert to $330 \mathrm{~mm}$ in the northern Oman mountain region, with a station average of $129 \mathrm{~mm} / \mathrm{a}$. The number of wet days (rainfall more than $1 \mathrm{~mm}$ ) over the same period varies from 2 to $32 \mathrm{~d}$ per year, with a station average of $12 \mathrm{~d}$ (Gunawardhana et al., 2018).
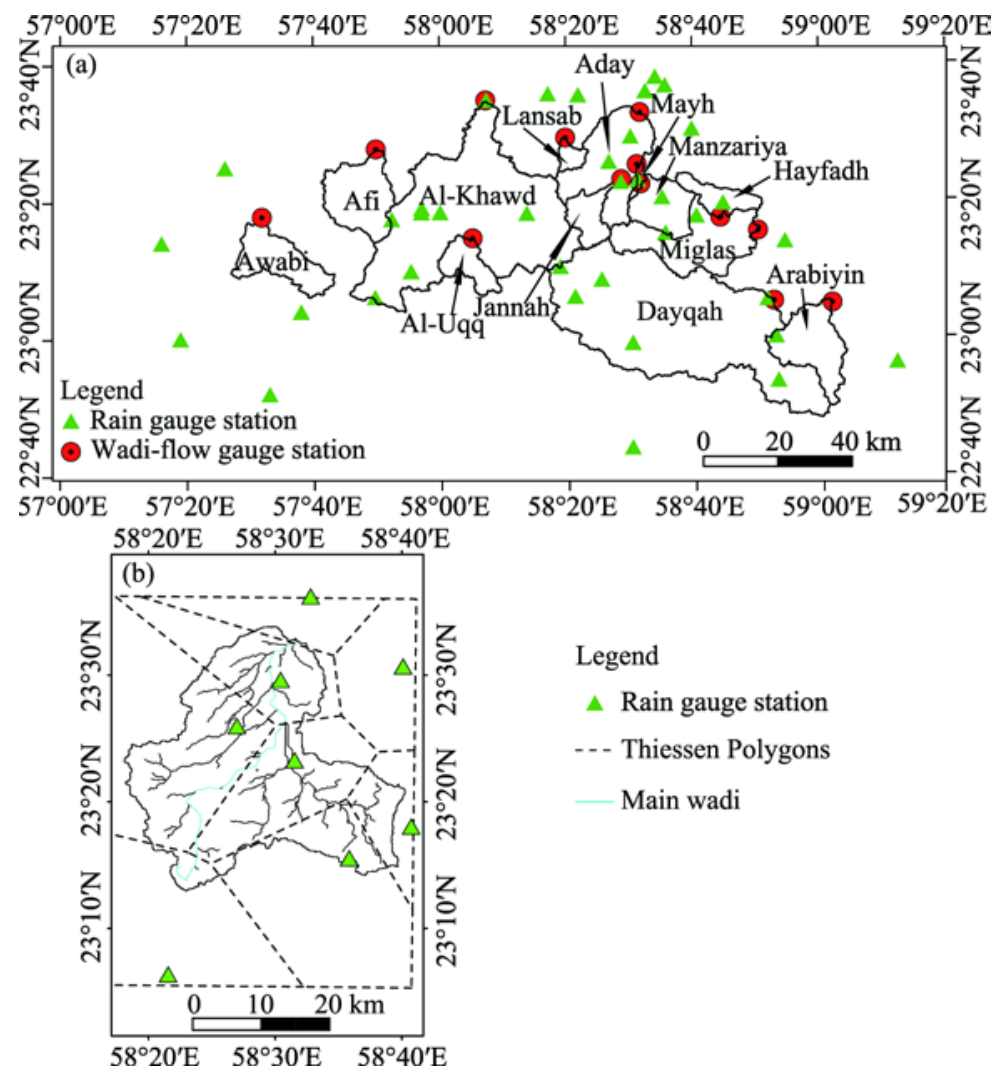

Fig. 1 Delineated catchments and locations of rain gauge stations (a) and Thiessen Polygons for Aday catchment (b) 
AlSarmi and Washington (2013) analyzed rainfall records at 23 stations covering 6 countries in the Arabian Peninsula including Oman for the period 1970-2008 and showed that the number of wet days with rainfall more than $10 \mathrm{~mm}$ significantly decreased. Gunawardhana and Al-Rawas (2016) studied rainfall records during the period 1990-2010 in three major coastal cities in Oman and found that the contribution from extreme rainfall to the annual total steadily increased. Moreover, Gunawardhana et al. (2018) predicted enhanced tropical cyclone activities in the northeast coastal region during 2040-2059 and 2080-2099 periods. This study also predicts decreases in number of rainy days and increases in rainfall intensity in many regions of the country. These research findings highlight the necessity of rainfall-runoff modeling in this region to cope with potential changes in rainfall regime in the future.

\section{Methodology}

The research methodology consists of three major steps: (1) delineation of the catchment areas and river-network using digital elevation model (DEM) data and extraction of watershed characteristics; (2) derivation of UHs at different time durations from observed river-flow and rainfall records; and (3) matching the physical characteristics of the watersheds with features of the corresponding UHs to develop hydro-morphological relations.

In the first stage, paired rainfall and river-flow data were collected to cover 12 major watersheds (Fig. 1). Observed river-flow at 5-min interval and tipping bucket rainfall measurements at 1-min interval were obtained from the Ministry of Regional Municipalities and Water Resources of Oman. Selected hydrograph cover a large extent of river-flow rates including the highest ever recorded during hurricane Gonu in 2007. Key catchment characteristics such as the watershed area, length of the main river and length to the centroid of the watershed along the main river from its outlet were derived from 40-m resolution DEM data and HEC-GeoHMS (Geospatial Hydrologic Modeling Extension) tool. The selected watersheds (Table 1) have a wide range of areas $\left(45-1660 \mathrm{~km}^{2}\right)$ and river lengths (13-92 km), which is a key need for generalizing results from small to large ungauged basins. In general, shape of the catchment area affects the magnitude and timing of the peak-flow (Nouh, 1990). The whole study area, which includes 12 major watersheds were then divided into 515 sub-catchments with various shapes and sizes. Basin shape factor, which was computed by dividing square of the river length by watershed area (Al-Rawas and Valeo, 2010), ranges from 0.5 (very circular) to 19.5 (extremely elongated). Similarly, sub-catchment areas extends over a wide range of 0.01 to $42.00 \mathrm{~km}^{2}$.

Table 1 List of stations and delineated catchment characteristics

\begin{tabular}{ccccc}
\hline Watershed & Wadi gauge & Area $\left(\mathrm{km}^{2}\right)$ & Wadi length $(\mathrm{km})$ & Length to the centroid $(\mathrm{km})$ \\
\hline Aday & FB505467AD & 794.2 & 54.6 & 25.2 \\
Afi & EL895407AD & 313.0 & 34.2 & 16.3 \\
Al Khawd & FB104840AD & 1660.2 & 91.9 & 39.6 \\
Al Uqq & FA160968AD & 132.1 & 22.5 & 8.2 \\
Arabiyin & GA057335AD & 303.8 & 37.7 & 18.9 \\
Hayfadh & FA777631AD & 122.2 & 21.7 & 7.4 \\
Lansab & FA395799AD & 44.7 & 13.3 & 8.5 \\
Manzariya & FA585595AD & 206.4 & 28.3 & 9.8 \\
Mayh & FA596055AD & 222.0 & 34.0 & 15.5 \\
Miglas & FA877343AD & 556.8 & 55.5 & 25.7 \\
Awabi & EL574613AD & 254.4 & 35.4 & 14.4 \\
Jannah & FA580672AD & 130.8 & 29.9 & 18.9
\end{tabular}

In the second stage, river-flow observations were aggregated to 10-min and 1-h durations when generating river-flow hydrographs. Similarly, 10-min and 1-h total rainfalls were calculated from tipping bucket rain gauge records to match with river-flow durations. When there are more than one rain gauge station correspond to a catchment area, the Thiessen Polygon method was used for 
averaging the rainfall time series. For example, the Thiessen Polygons developed for the Aday catchment area are shown in Figure 1b. There are no perennial river-flow in these watersheds. In fact, most of the watersheds in arid regions have ephemeral-type rivers that produce water flow temporally during the rainfall and dried up immediately due to extremely high evaporation demand and infiltration rate. Therefore, base-flow is essentially negligible and excess rainfall volume is equal to the integrated area under the hydrograph. The reverse process of the discrete $\mathrm{UH}$ convolution technique, known as the deconvolution method (Chow et al., 1988), was applied to derive a UH from river-flow and excess rainfall. Excess rainfall was calculated by the constant fraction loss model (McCune, 1998; Dingman, 2015), where a certain percentage of rainfall become runoff. Corresponding mathematical equation can be expressed as:

$$
\begin{aligned}
& i(t)=C_{r} p(t) \\
& C_{r}=\frac{\int Q(t) d t}{A \int p(t) d t},
\end{aligned}
$$

where $i(t)$ is the excess rainfall rate $(\mathrm{m} / \mathrm{h}) ; p(t)$ is the observed rainfall rate $(\mathrm{m} / \mathrm{h}) ; C_{r}$ is the fraction of rainfall converts to runoff; $A \int p(t) d t$ is the rainfall volume $\left(\mathrm{m}^{3}\right) ; A$ is the watershed area $\left(\mathrm{m}^{2}\right)$; and $\int Q(t) d t$ is the cumulative wadi-flow volume $\left(\mathrm{m}^{3}\right)$.

In the third stage of this research, the basics of the Snyder's empirical relationship was followed to relate UH features with the physical characteristics of the watershed. According to Snyder (1938), lag-time $\left(t_{p}\right)$, which is defined as the time from the center of mass of excess rainfall to the peak-flow rate, is given by:

$$
t_{p}=C_{t}\left(L \times L_{c}\right)^{n},
$$

where $L$ is the main wadi length from the most upstream point of the watershed to the catchment outlet $(\mathrm{km}) ; L_{c}$ is the distance from the catchment outlet to the point along the main wadi which is the closest to the centroid of the watershed $(\mathrm{km})$; and $C_{t}$ and $n$ are parameters which depends on particular catchment characteristics. Snyder (1938) calibrated $n=0.3$ by analyzing a large number of hydrographs in Appalachian Highland of eastern United State. Since then, many studies used the same value without proper calibration into local conditions including in arid regions (Sen, 2008; Sudhakar et al., 2015). In this study, parameters $n$ and $C_{t}$ were calibrated by matching the properties of the derived UHs. Also, according to Snyder (1938), the peak-flow rate is given as follows:

$$
Q_{p}=\frac{\left(2.78 C_{p} \times A\right)}{C_{t}\left(L \times L_{c}\right)^{n}},
$$

where $Q_{p}$ is the peak-flow rate $\left(\mathrm{m}^{3} / \mathrm{s}\right) ; C_{p}$ is a parameter which depends on the storage and retention characteristics of the watershed; and $A$ is the catchment area $\left(\mathrm{km}^{2}\right)$. In this study, a relationship between $L$ and $L_{c}$ was developed by considering the 515 sub-catchments delineated in the first step. Because $C_{p}$ and $C_{t}$ depend on particular catchment characteristics, they were combined together to form a single parameter ( $C$ in Eq. 4). It was later calibrated by matching the properties of the derived UHs. Accordingly, the relationship between $L$ and $L_{c}$ will simplify the Equation 3, where $Q_{p}$ can be estimated in terms of two physical features of the watershed: $L$ and $A$ as in Equation 4 .

$$
Q_{p}=\frac{C \times A}{(L)^{m}},
$$

where the exponent $m$ can be calculated based on the relationship between $L$ and $L_{c}$.

\section{Results and discussion}

\subsection{Extraction of catchment characteristics from DEM data}

Until recently, basic catchment characteristics, such as the watershed area and wadi-length, were 
derived from topographic map sheets manually. Some watershed parameters, such as the slope and the centroid of the area, are not readily available through manual delineation, but must be calculated. It therefore is difficult to estimate them with sufficient accuracy. As DEM data and automatic catchment delineation become widely popular, reliability of the parameter estimations significantly improved. However, it requires certain experience and sophisticated software, which may not be available yet among designers and practitioners at local government levels. Therefore, this study was planned to reduce the number of parameters required to estimate flood hydrograph, and presents it based on certain parameters, which are easily achievable. Accordingly, a relationship between $L$ and $L_{c}$ was developed. Out of the 515 sub-catchments delineated, half of them were used to develop the relationship (Fig. 2a) and rest were used for model validation (Fig. 2b). This relationship was further validated with the information delineated from 12 major watersheds (Fig. 2c). All three relationships included various catchment areas with different shapes, and produced higher coefficients of determination $\left(R^{2}>0.89\right)$. This relationship therefore can be successfully applied in Equation 3 to simplify the estimations of $Q_{p}$ (Eq. 4).

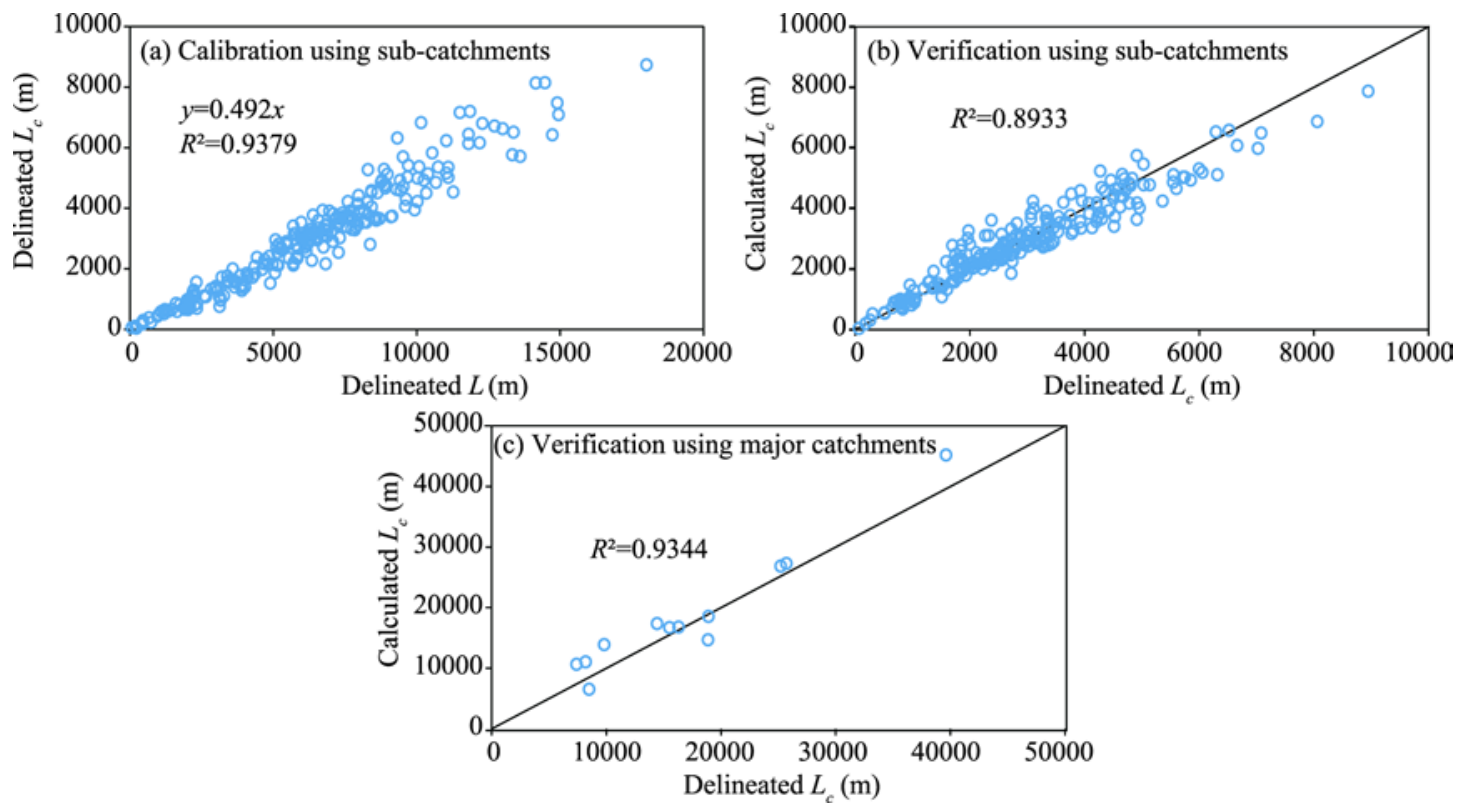

Fig. 2 Calibrated and validated relationship between $L$ (the main wadi length from the most upstream point of the watershed to the catchment outlet) and $L_{c}$ (the distance from the catchment outlet to the point along the main wadi which is the closest to the centroid of the watershed)

\subsection{Derivation of UHs at different time durations}

Eight of the 12 major watersheds studied were used for developing the relationships to calculate lag-time and peak-flow rate of the UH (Eqs. 2 and 4, respectively) and remaining four watersheds were used for verifying those relationships. The observed wadi-flow rates at 10 -min and 1-h intervals along with the calculated excess rainfall (Eq. 1) at same durations were used with the deconvolution method to estimate the corresponding UHs. In verification stage, above UHs were applied with different rainfall events to calculate resultant wadi-flow. Figure 3 presents the observed and simulated wadi-flows for calibration and verification of 1-h UHs. The UHs were calibrated using short duration rainfall events, yielding a well-defined single peaked hydrograph of short time base, and verified using the events with the highest observed peak-flow. Four of the eight major watersheds were verified with observed wadi-flows occurred during Cyclone Gonu in 2007. When there are more than two hydrographs available for a catchment area, they were all used for verifying the calibrated UHs. The coefficients of determination $\left(R^{2}>0.89\right)$ evident for a good agreement between observed and simulated wadi-flows. Some level of differences between observed and simulated wadi-flows can be attributed not only to the limitations of the model itself 
but also to the various issues such as observational errors of wadi-flows and rainfalls, and inadequacy of the meteorological stations to capture the spatial distribution of the rainfall events.
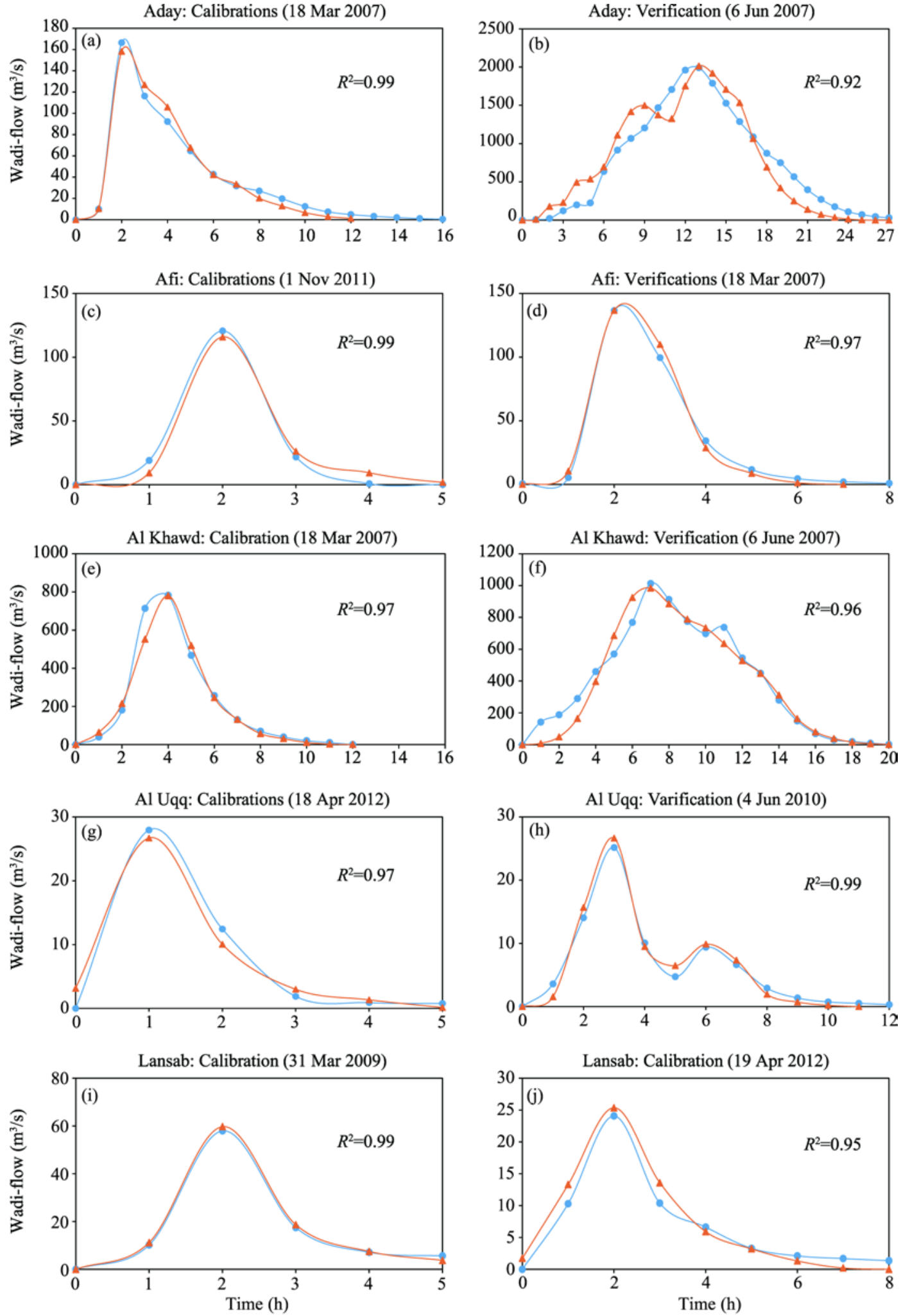

$\because$ Observation $\rightarrow$ Simulation 

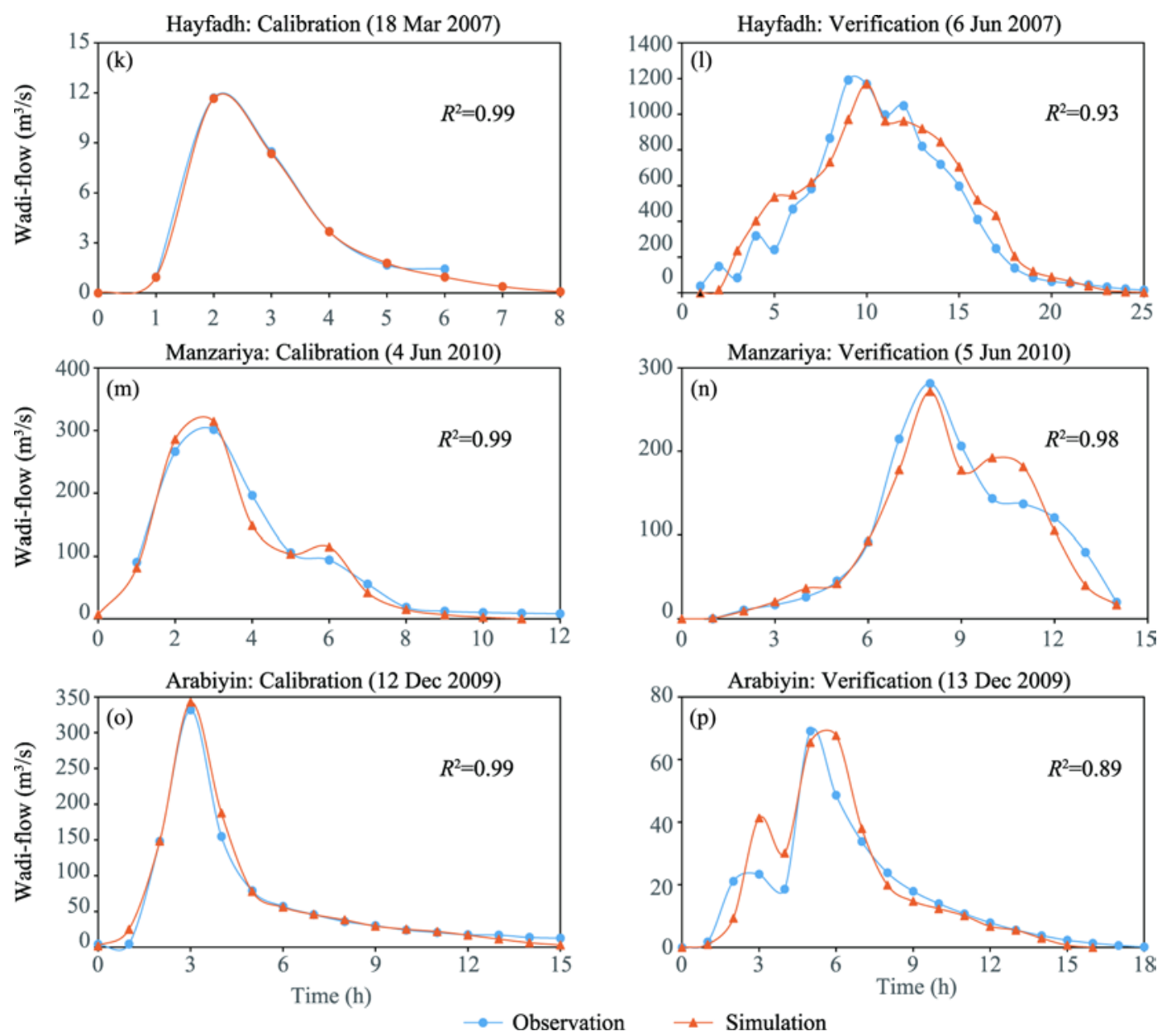

Fig. 3 Observed and simulated wadi-flow using 1-h UH (unit hydrograph)

When a UH of a given excess-rainfall duration is available, the principle of superposition (Shydrograph method) can be used to derive the UHs of any required duration (Chow et al., 1988). Accordingly, 1-h UHs developed in the previous stage were used to calculate 10-min UHs. Also, another set of 10-min UHs were derived using 10-min rainfall and wadi-flow data applied with the deconvolution method. Figure 4 depicts a marked difference of the 10-min UHs developed by these two methods for Aday watershed. Similar phenomenon in different magnitudes were observed in all watersheds where the 10-min UH developed by the 10-min rainfall and wadi-flow data produced a greater peak-flow. The reason for this difference can be attributed to the assumptions made in deriving UHs. For example, it is assumed that the excess rainfall is uniformly distributed over the entire watershed at a constant rate for the selected duration. This assumption, under natural conditions in arid regions, can rarely be satisfied. Arid regions experience occasional rainfall events with intensity varies significantly over time (Greenbaum et al., 1998). Therefore, such difference between theoretical S-hydrograph method and the deconvolution method with real data can be expected. Figure 5 shows the peak-flow simulated by these two methods and their match with the observed 10-min averaged peak-flow. It is noted that the UH derived from the S-hydrograph method underestimated the peak-flow up to $30 \%$ while the deconvolution method with short-term real data produced promising results. It is also clear that this difference between the observed and simulated peak-flows by the S-hydrograph method increases as the catchment area increase. These results therefore demand appropriate modifications for existing methods used for wadi-flow estimation in arid regions. 


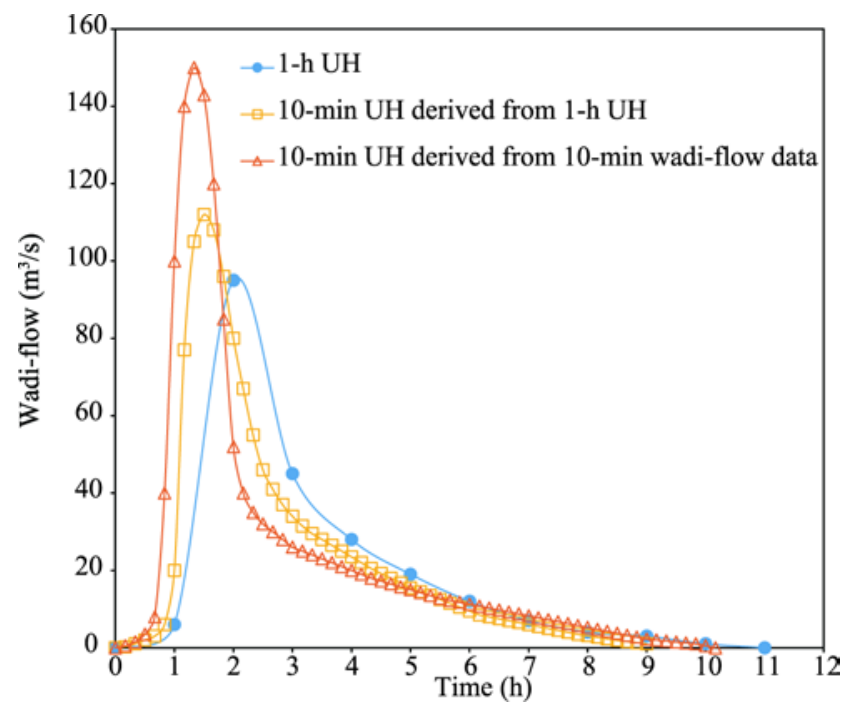

Fig. 4 Comparison of 10-min UHs developed by two methods for Aday catchment

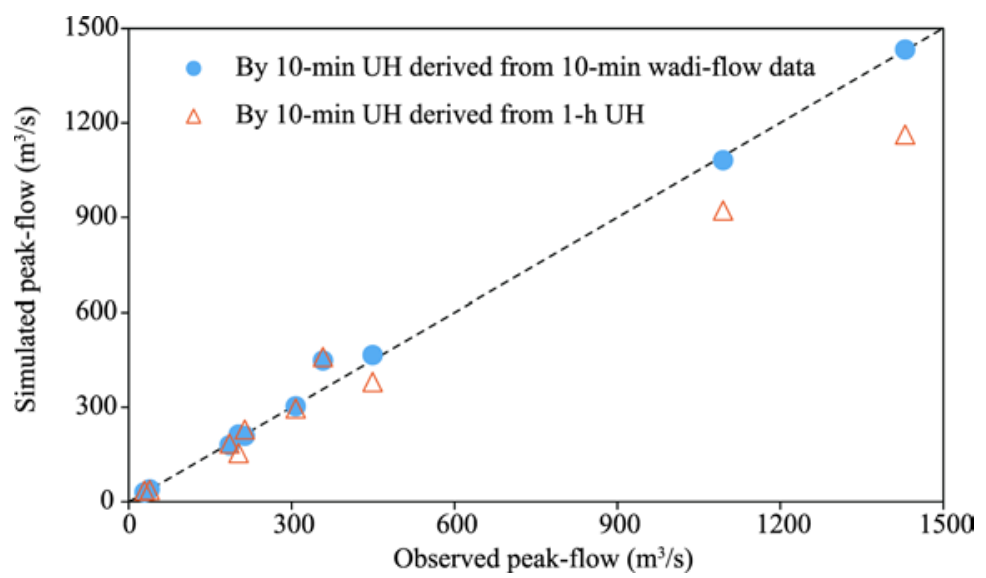

Fig. 5 Observed and simulated 10-min averaged peak-flows by two methods for all watersheds

\subsection{Relationship of UH features with physical characteristics of watersheds}

\subsubsection{Peak-flow}

According to Snyder (1938), peak-flow $\left(Q_{p}\right)$ can be expressed as a function of three physical characteristics of a watershed: area $(A)$, length of the main wadi $(L)$ and length to the centroid of the watershed $\left(L_{c}\right)$ (Eq. 3). Based on the relationship developed between $L$ and $L_{c}$ in Figure 2a, Equation 4 can be used to estimate $Q_{p}$ as a function of $A$ and $L$. Accordingly, the peak-flows taken from the derived UHs and delineated catchment characteristics (Table 1) were used with the leastsquare method to obtained parameters $C$ and $m$. Figure 6a depicts a comparison of the peak-flows taken from the derived UHs and the ones derived with estimated $C$ and $m$. Because the objective of this study is to develop a methodology that is easily adaptable in designs, it is important to keep calibrated parameters unified for different time durations. Accordingly, the calibrated $m$ value of 0.7 was applied with the peak-flows from the derived 10-min UHs. Figure 6b shows that the peakflow matches with the $A / L^{0.7}$ ratio reasonably well $\left(R^{2}=0.98\right)$. Hence, $m=0.7$ can be used in estimating peak-flow of UHs at 1-h and 10-min durations, and it might be applicable for other durations as well. The differences between the 1-h and 10-min UHs for various features, such as the peak-flow and lag-time, can be accounted by markedly different gradients of the two graphs (1.89 and $3.01 \mathrm{~m}^{3} /\left(\mathrm{s} \cdot \mathrm{km}^{1.3}\right)$ for 1-h and 10-min UHs, respectively). 

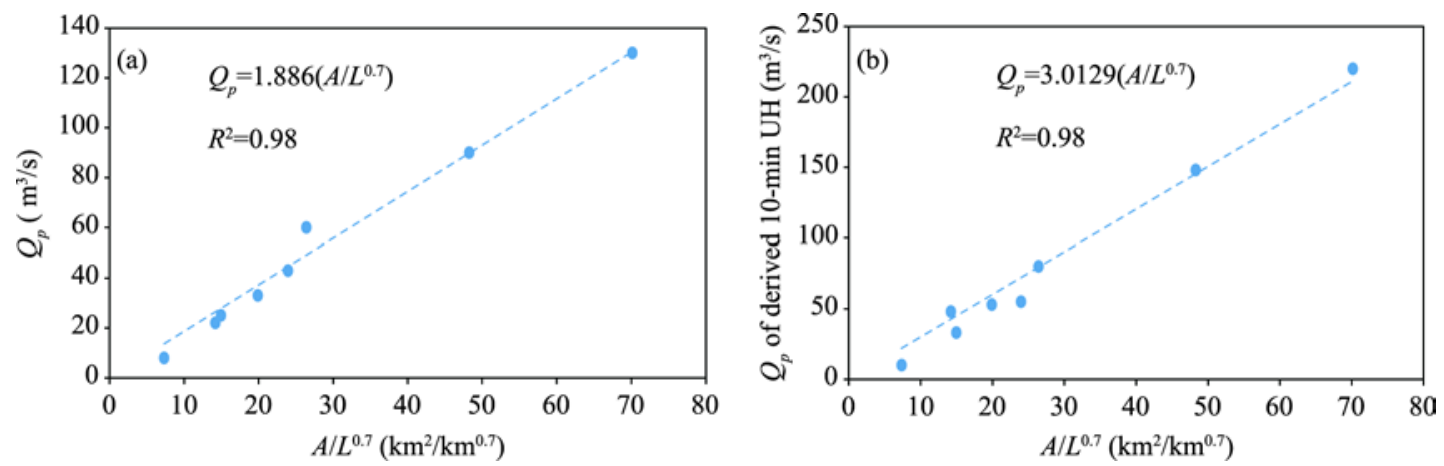

Fig. 6 Relationship between peak-flow $\left(Q_{p}\right)$ and physical characteristics of the catchment derived using the optimal $m$ value (0.7) for 1-h and 10-min UHs (unit hydrographs)

\subsubsection{Lag-time}

The lag-time $\left(t_{p}\right)$ is defined as the time from the center of mass of excess rainfall to the peak-flow rate, which according to Equation 2 can be expressed as a function of the length of the main wadi $(L)$ and length to the centroid of the watershed from its outlet $\left(L_{c}\right)$. Theoretically, the lag-time of the 10-min UH should be smaller than that of the 1-h UH (Fig. 4). When the $n$ parameter of the Equation 2 is calibrated $(n=0.35)$ and fixed for any time duration, remaining parameter $C_{t}$ should be varied to account the difference between 10-min and 1-h UHs. Figure 7 shows the calibrated $C_{t}$ for estimating lag-time for the 1-h and 10-min UHs. The relationship between $t_{p}$ and $\left(L \times L_{c}\right)^{0.35}$ for the 1-h UH produce only a moderate agreement with a coefficient of determination equals to 0.74 . This is because the lag-time for 1-h UHs can only be estimated with a $\pm 0.5 \mathrm{~h}$ accuracy. When actual lag-time of different catchments varies within a smaller range (1.0-3.5 h as in Fig. 7), such uncertainty in estimating $t_{p}$ can be significant. Due to the finer time resolution, the relationship between $t_{p}$ and $\left(L \times L_{c}\right)^{0.35}$ for the 10-min UH produces good agreement with a coefficient of determination equals to 0.98 .
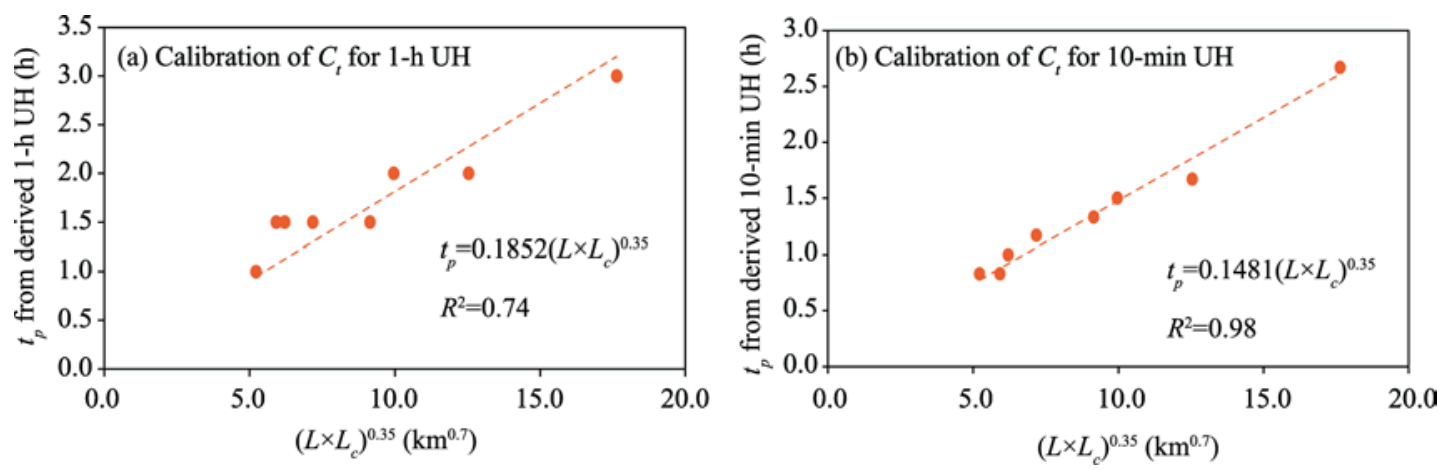

Fig. 7 Calibration of $C_{t}$ (Equation 2) for estimating lag-time for the 1-h and 10-min UHs

\subsubsection{Time-widths}

Sections 4.3.1 and 4.3.2 present quantitative analyses to estimate the peak-flow and lag-time. However, in order to determine the shape of the UH, few more ordinates on the UH must be known. Snyder (1938) expressed the time-width of the UH at a discharge equal to a certain percent of the peak-flow as a function of peak-flow rate per unit watershed area. It was further assumed that onethird of this width is distributed before the UH peak time and two-third after the peak (Chow et al., 1988; Angelidis et al., 2010). Accordingly, three relationships were developed for the time-width at $75 \%, 50 \%$ and $30 \%$ of the peak-flow based on the derived UHs (Fig. 8). It is clear that the timewidth is inversely proportional to the peak-flow per unit watershed area. All six graphs produced relatively acceptable relationships with determination coefficient more than 0.87 . These empirical equations provide six more points on the $\mathrm{UH}$, which brings altogether eight ordinates to determine 
the probable shape of the UH.
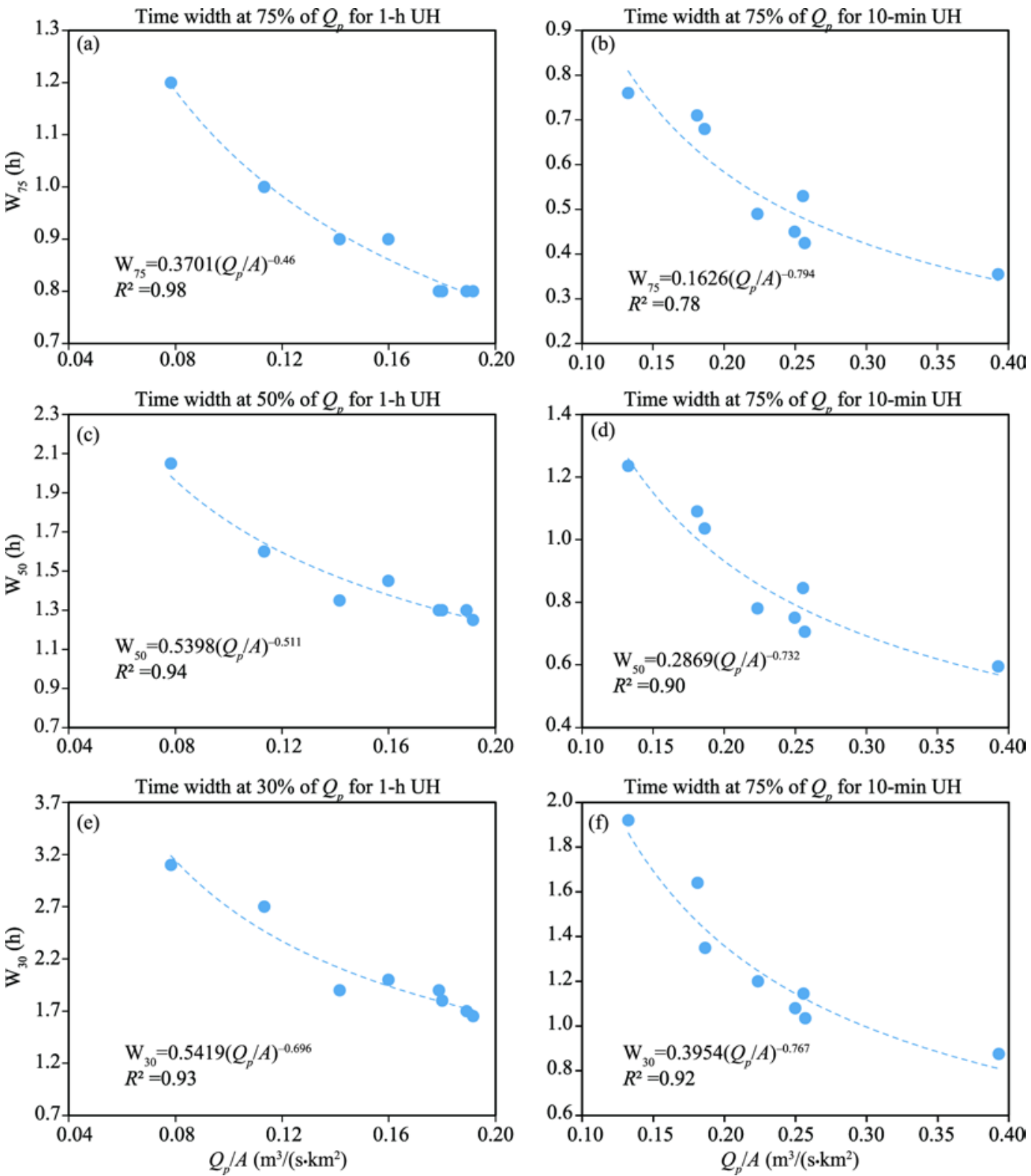

Fig. 8 Time width at 75\% ( $\left.\mathrm{W}_{75}\right), 50 \%\left(\mathrm{~W}_{50}\right)$ and 30\% $\left(\mathrm{W}_{30}\right)$ of the $Q_{p}$ for 1-h and 10-min UHs. $A$, catchment area.

Rainfall-runoff hydrographs in arid regions can be quite distinct from those in humid regions. Attributed to the steep slope, flow is faster in arid regions resulting in shorter rising limb and greater peak-flow. The total discharge significantly decreases within short periods of time due to high rates of evaporation and transmission loss. Wadi-beds in these regions are generally composed of alluvial sediments dominated by highly permeable coarser grain sizes. Therefore, 1:2 width-ratio as suggested by Snyder (1938) may not be applicable in arid regions. A series of UHs was developed for 1-h and 10-min durations for all study areas based on empirical relationships developed in previous steps (Figs. 2, 6, 7 and 8). When compare these UHs with ones derived from observed wadi-flow, it was determined that the 3:4 width-ratio produced better results than the 1:2 widthratio. For example, Figure 9 shows a comparison of 10-min UHs developed for Afi watershed with two different width-ratios. It is clear that the 3:4 width-ratio formed shorter rising limb than the 1:2 width-ratio and matches better with the derived UH from observed wadi-flow. 


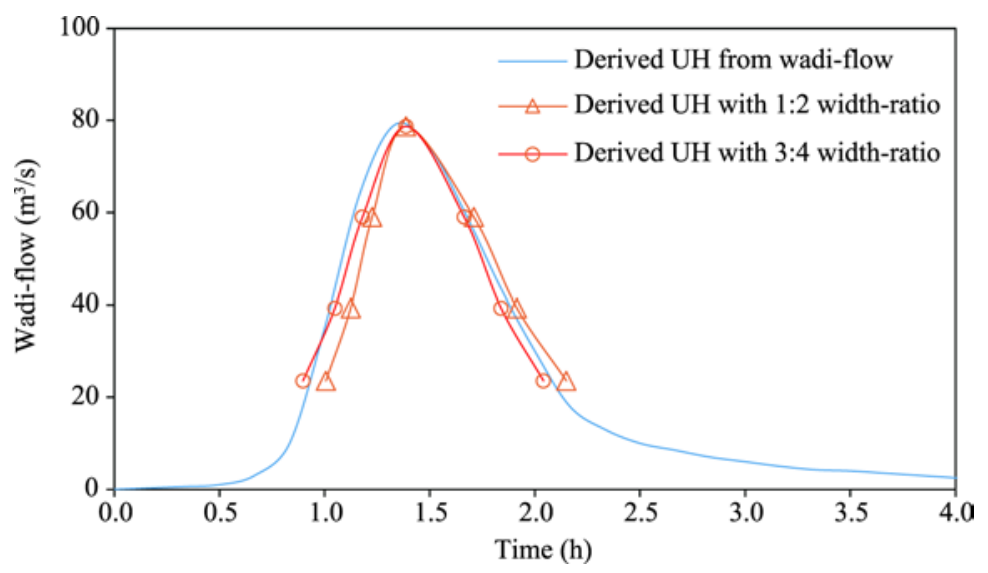

Fig. 9 Comparison between developed 10-min UHs for Afi watershed with two different width-ratios

The applicability of the proposed empirical equations to develop the UHs at 1-h and 10-min durations was tested by simulating wadi-flows in four more watersheds. These four watersheds are different to those used for calibrating and verifying UHs in Figure 3, whose catchment characteristics are shown in Table 1. Figure 10 shows the observed and simulated hydrographs based on the empirical equations proposed. It is clear that the simulations by the 1-h UHs agree better with the observations than the results from the 10-min UHs. When simulating wadi-flows at finer time resolutions, uncertainty arises due to temporal and spatial variations of rainfall events, especially in arid regions. However, time averaged 1-h wadi-flows smooth the abrupt variations at 10-min interval and therefore produced better agreements. All simulations reasonably capture different features of the hydrographs, such as the general trend, peak-flow, time-lag etc., when match with the observations. It therefore indicates that the developed empirical relationships can be applied in deriving UHs particularly for arid regions in Oman. These results can further be improved by applying them in different countries with similar climate and geographical settings.

\section{Conclusions}

Rainfall-runoff relationship in arid regions is unique and proper understanding is challenging. This study aimed in developing a simple but reliable procedure for estimating $\mathrm{UH}$ at reasonably finer time resolutions (10-min and 1-h) which can be easily adaptable by practitioners at sub-catchment levels, especially when it is ungauged. For example, wadi length can easily be estimated by automatic delineation from DEM data or even by manual methods. However, calculation of the catchment centroid is rather difficult, especially when paper based topographic maps are used. Results of this study indicate that the strong relationship found between the wadi length and the length to the centroid of the catchment area can be adopted to simplify the existing methods to determine UHs. Moreover, it was found that the principle of superposition with the assumption of uniform excess rainfall distribution would not be applicable in arid regions. A marked difference was found between the 10-min UHs estimated by the S-hydrograph method and deconvolution method. Therefore, it is concluded that a method depends on natural hydro-meteorological conditions would be more practical in arid region.

A set of empirical equations were developed for estimating peak-flow, lag-time and time-widths at $75 \%, 50 \%$ and $30 \%$ of the peak-flow for 10 -min and 1-h UHs by analyzing wadi-flows in eight watersheds. Developed relationships were successfully validated with observed wadi-flows in four independent watersheds. When calibrated parameters are concerned, developed empirical relationships are quite distinct from those suggested for other regions. For example, the 3:4 widthratio was found to be more suitable in arid regions than 1:2 width-ratio suggested in numerous past studies. The proposed methodology is expected to be useful for water resources management in arid regions, especially for planning countermeasures to cope with future climate change. 

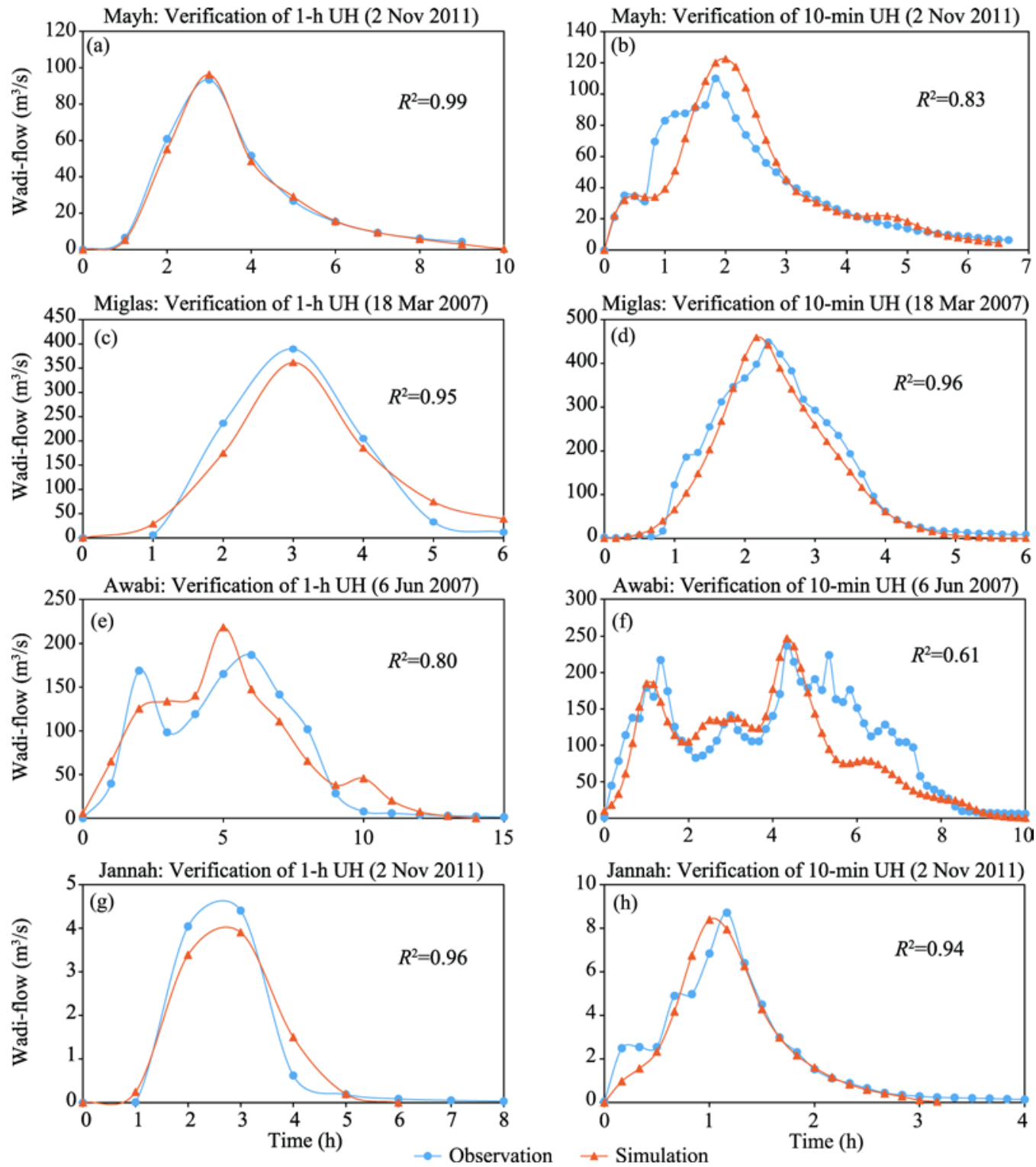

Fig. 10 Comparison of observed and simulated wadi-flows from proposed empirical equations

\section{Acknowledgements}

The data of this study were obtained from the Ministry of Regional Municipality and Water Resources (MRMWR), Oman to be used for research purposes only. The data are not publicly available but can be requested from MRMWR.

\section{References}

Abdalla F, Shamy I, El Bamousa A O, et al. 2014. Flash floods and groundwater recharge potentials in arid land alluvial basins, Southern Red Sea Coast, Egypt. International Journal of Geosciences, 5(9): 971-982.

Abdalla O, Al-Rawahi A S. 2013. Groundwater recharge dams in arid areas as tools for aquifer replenishment and mitigating seawater intrusion: example of AlKhod, Oman. Environmental Earth Sciences, 69: 1951-1962.

Ahmadalipour A, Moradkhani H. 2019. A data-driven analysis of flash flood hazard, fatalities, and damages over the CONUS during 1996-2017. Journal of Hydrology, 578: 124106.

Al-Rawas A G, Valeo C. 2010. Relationship between wadi drainage characteristics and peak-flood flows in arid northern Oman. Hydrological Sciences Journal, 55(3): 377-393. 
AlSarmi S H, Washington R. 2013. Changes in climate extremes in the Arabian Peninsula: analysis of daily data. International Journal of Climatology, 34(5): 1329-1345.

Angelidis P, Kotsikas M, Kotsovinos N. 2010. Management of upstream dams and flood protection of the Transboundary River Evros/Maritza. Water Resources Management, 24: 2467-2484.

Badrzadeh H, Sarukkalige R, Jayawardena A W. 2015. Hourly runoff forecasting for flood risk management: application of various computational intelligence models. Journal of Hydrology, 529: 1633-1643.

Bhuyan M K, Kumar S, Jena J, et al. 2015. Flood hydrograph with synthetic unit hydrograph routing. Water Resources Management, 29: 5765-5782.

Borga M, Capovilla A, Cazorzi F, et al. 1991. Development and application of a real-time flood forecasting system in the Veneto region of Italy. Water Resources Management, 5: 209-216.

Chow V T, Maidment D R, Mays L W. 1988. Applied Hydrology. New York: McGraw-Hill, 213-230.

Clark C O. 1943. Storage and the unit hydrograph. Proceedings of the American Society of Civil Engineers, 69(9): 1333-1360.

Dingman S L. 2015. Physical Hydrology ( $3^{\text {rd }}$ ed.). Illinois: Waveland Press Inc., 455-514.

El Hassan A A, Sharif H O, Jackson T, et al. 2013. Performance of a conceptual and physically based model in simulating the response of a semi-urbanized watershed in San Antonio, Texas. Hydrological Processes, 27(24): 3394-3408.

Ghoneim E, Foody G M. 2013. Assessing flash flood hazard in an arid mountainous region. Arabian Journal of Geosciences, 6 : 1191-1202.

Gray D M. 1961. Synthetic unit hydrographs for small watersheds. Journal of Hydraulics Division, 87(HY4): 33-54.

Greenbaum N, Margalit A, Schick A B, et al. 1998. A high magnitude storm and flood in a hyperarid catchment, Nahal Zin, Negev Desert, Israel. Hydrological Processes, 12(1): 1-23.

Gunawardhana L N, Al-Rawas G A. 2016. A comparison of trends in extreme rainfall using 20-year data in three major cities in oman. The Journal of Engineering Research, 13(2): 137-148.

Gunawardhana L N, Al-Rawas G A, Kwarteng A Y, et al. 2017. Potential changes in the number of wet days and its effect on future intense and annual precipitation in northern Oman. Hydrology Research, 49(1): 237-250.

Hering D, Gerhard M, Manderbach R, et al. 2004. Impact of a 100-year flood on vegetation, benthic invertebrates, riparian fauna and large woody debris standing stock in an alpine floodplain. River Research and Applications, 20(4): 445-457.

Jena S K, Tiwari K N. 2006. Modeling synthetic unit hydrograph parameters with geomorphologic parameters of watersheds. Journal of Hydrology, 319(1-4): 1-14.

Kazama S, Sato A, Kawagoe S. 2009. Evaluating the cost of flood damage based on changes in extreme rainfall in Japan. Sustainability Science, 4: 61-69.

Mayaud C, Gabrovšeka F, Blatnika M, et al. 2019. Understanding flooding in poljes: A modelling perspective. Journal of Hydrology, 575: 874-889.

McCune R H. 1998. Hydrologic analysis and design (2 ${ }^{\text {nd }}$ ed.). New Jersey: Prentice Hall, 489-493.

Merz B, Kreibich H, Schwarze R, et al. 2010. Assessment of economic flood damage. Natural Hazards and Earth System Sciences, 10: $1697-1724$.

Nouh M. 1990. Flood hydrograph estimation from arid catchment morphology. Hydrological Processes, 4(2): $103-120$.

Parsons M. 2018. Extreme floods and river values: A social-ecological perspective. River Research and Applications, 35(10): 1677-1687.

Pilgrim D H, Chapman T G, Doran D G. 1988. Problems of rainfall-runoff modelling in arid and semiarid regions. Hydrological Sciences, 33: 379-400.

Sen Z. 2008. Modified hydrograph method for arid regions. Hydrological Processes, 22(3): 356-365.

Sherman L K. 1932. Streamflow from rainfall by the unit-graph method. Engineering News Record, 108: 501-505.

Snyder F F. 1938. Synthetic unit-hydrographs. Eos Transactions American Geophysical Union, 19(1): 447-454.

USDA-SCS (United States Department of Agriculture-Soil Conservation Service). 1972. National Engineering Handbook, Section 4-Hydrology. Washington D C: USDA-SCS.

Sudhakar B S, Anupam K S, Akshay O J. 2015. Snyder unit hydrograph and GIS for estimation of flood for un-gauged catchments in Lower Tapi Basin, India. Hydrology Current Research, 6(1): 1-10.

Sugawara M. 1995. Tank model, computer models of watershed hydrology, In: Singh V P. Computer Models of Watershed Hydrology. Colorado: Water Resources Publications, Highlands Ranch, 1130.

Tomirotti M, Mignosa P. 2017. A methodology to derive synthetic design hydrographs for river flood management. Journal of Hydrology, 555: 736-743.

Usul N, Tezcan B. 1995. Determining synthetic unit hydrographs and parameters for four Turkish basins. Journal of Soil and Water Conservation, 50(2): 170-173.

Young M E, Macumber P G, Watts M, et al. 2004. Electromagnetic detection of deep freshwater lenses in a hyper-arid limestone terrain. Journal of Applied Geophysics, 57(1): 43-61. 